\title{
Impact of sustained remission on quality of life among women with rheumatoid arthritis and systemic lupus erythematosus: a prospective observational study
}

Basant Elnady ${ }^{1,2^{*}}$ (D, Azza Taha ${ }^{3,4}$, Dalia E. Desouky ${ }^{3,4}$, Shorouk F. Abd-Elmakoud ${ }^{5}$, Elsayed M. Rageh ${ }^{6}$, Abdulmajeed M. Algethami ${ }^{7}$, Mohamed Algethami ${ }^{8}$, Peter M. ten Klooster ${ }^{9}$ and Johannes J. Rasker ${ }^{9}$

\begin{abstract}
Background: Health-related quality of life (HRQOL) as a patient reported outcome plays important roles in the life of patients with RA (rheumatoid arthritis) and SLE (Systemic lupus erythematosus) as well as their families. Evaluating the impact of sustained remission on HRQOL is important and could be of potential help in daily practice. Thus, we aimed to assess and compare prospectively the impact of sustained remission on HRQOL in Saudi RA and SLE female cohorts.

Results: Sixty-two female patients with active RA and 34 female patients with active SLE fulfilled the inclusion-, entry- and follow-up criteria. At baseline, the SLE patients had significantly better SF-36 scores than the RA patients. In both groups, significant correlations were found between disease activity and physical (PCS) and mental (MCS) components summary of the SF-36 (all $p^{\prime} s \leq 0.001$ ). In sustained remission, both SLE and RA patients showed significant improvements of the SF-36 scores $(p<0.001)$ compared to baseline. RA patients in sustained remission had a significantly better general health, bodily pain and physical functioning, and total PCS scores $(p<0.001)$ than those with SLE.

Conclusions: Both SLE and RA patients in sustained remission showed strongly improved HRQOL. In sustained remission, RA patients had comparable or better HRQOL than SLE patients.
\end{abstract}

Keywords: Remission, Quality of life, Rheumatoid arthritis, Systemic lupus erythematosus, Disease activity

\section{Background}

Rheumatoid arthritis (RA) is a chronic inflammatory autoimmune disorder that may lead to joint inflammation, deformities, and organ involvement [1]. Physical deformities, painful disabilities, and impairment may all contribute to depression in people with RA [2]. Depression is estimated to be five times more common in

\footnotetext{
* Correspondence: basantelnady@gmail.com

${ }^{1}$ Department of Rheumatology, Rehabilitation and Physical Medicine, Benha University, Banha, Egypt

${ }^{2}$ Rheumatology Department, Al-Hada Armed Forces Hospital, Taif, Saudi

Arabia

Full list of author information is available at the end of the article
}

people with RA than in the general population [3]. The combination of RA and depression has been shown in a number of studies to increase impairment and lower quality of life [4-6]. Also, in the early stages of the disease, RA patients were found to have lower levels of health-related quality of life (HRQOL) than the general population [6].

Systemic lupus erythematosus (SLE) is a systemic autoimmune rheumatic disease affecting 1-12 people per 5000 worldwide [7]. Depressive conditions are prevalent in 17-75 percent of SLE patients, according to studies $[8,9]$. Depression was found to be more common in SLE patients than in the general population [10] and was 
found to be a significant indicator of poor HRQOL in those patients [11].

Studies have found a connection between RA patients' disease behavior and the presence of depression, as well as a reduction in HRQOL [4, 5, 12-14]. The same was found in SLE patients, who had stronger HRQOL when they had a longer clinical recovery and less disease activity $[9,12,15-17]$. Although the impact of disease activity on HRQOL has been studied in the past, the impact of disease remission, particularly sustained remission, has yet to be investigated in Arab patients. In addition, little is known about the effects of remission in RA versus SLE. Just one prospective study in Mexican RA and SLE patients was identified in a thorough literature review, comparing the impact of disease remission, in particular of sustained remission, has hardly been studied yet in Arab patients. Also, very little is known about the differential impact of remission in RA and SLE. A careful literature search found only one prospective study in Mexican RA and SLE patients, comparing the effect of remission on HRQOL of both RA and SLE patients [18].

Recently, the remission criteria of RA and SLE patients have been clearly defined $[18,19]$. As HRQOL plays an important role in the lives of patients with RA and SLE as well as their families, evaluating the impact of sustained remission on HRQOL is important and could be of potential help in daily practice. It is expected that prolonged remission will improve QOL in both RA and SLE. But it is necessary to gather real life data and confirm our beliefs.

As these data are lacking in Arab populations, we decided to assess and compare the impact of sustained remission on HRQOL in two cohorts of Saudi RA and SLE female patients.

\section{Methods}

\section{Study design}

This study was a prospective comparative observational study among RA and SLE patients. Adult female Saudi RA patients $>18$ years who fulfilled the 2010 RA classification criteria [19] with active 28-joint disease activity score (DAS28 > 3.2) [20] and adult female Saudi SLE patients who fulfilled the American College of Rheumatology (ACR) classification criteria [21] with active Systemic Lupus Disease Activity Index scores (SLEDAI > 4) [22] visiting the outpatient rheumatology clinics of the Al Hada Armed Forces Hospital, Taif, Saudi Arabia, were invited consecutively by a rheumatologist from January to June 2016 (6 months) to participate in the study.

All patients underwent full clinical and laboratory assessment. The DAS28-ESR [20] was measured by rheumatologists in the RA patients at baseline of the study and every 3 months during 2 years follow-up. The
SLEDAI [22, 23] was measured by rheumatologists in the SLE patients at baseline of the study and every 3 months during 2 years follow-up. Patient-reported HRQOL was assessed with the SF-36 health survey at baseline and in patients after sustained remission $[6,11]$. The primary outcomes were HRQOL in RA and SLE patients in sustained remission compared with baseline data.

\section{Inclusion criteria}

Only patients achieving sustained remission that persisted for at least 2 consecutive clinic visits over 8 months were included. RA remission was defined when DAS28 $\leq 2.6$ and SLE remission with clinical SLEDAI$2 \mathrm{~K}$ of 0 and a physician global assessment $\leq 2$.

\section{Exclusion criteria}

Patients with active neuropsychiatric lupus, other autoimmune disease, and chronic comorbidities such as thyroid disorder, diabetes, hypertension, heart failure, and stroke were excluded. Patients known to have psychiatric related illness were also excluded at initial study screening.

\section{Definitions of remission}

The SLE patients in remission were defined according to the Definition of Remission in SLE (DORIS) remission criteria with a clinical SLEDAI-2K of 0 and a physician global assessment $\leq 2$ and with excluding the items 'hypocomplementemia' and 'anti-dsDNA [24]. During the sustained remission, the patients needed to be on stable treatment. In both groups, the treatment was allowed to include a maintenance dosage of antimalarials and stable maintenance dose of immunosuppressive agents and/or biologic disease modifying antirheumatic drugs and stable dose of low-dose glucocorticoids $\leq 5 \mathrm{mg}$ prednisone daily. If recently a higher dosage of glucocorticoids and/or immunosuppressive drugs were used to treat increased disease activity a patient was not considered in remission.

RA remission was defined when DAS28 $\leq 2.6$. According to Smolen et al. [25] RA treat to target sustained remission was defined as achieving remission or low disease activity continuously maintained for a minimum of 6 months. However, the duration to consider sustained remission in SLE has not yet been clearly defined in literature. Therefore, the recommendation to have at least 6 months remission or low disease activity prior to getting pregnant [26] can also be considered sustained remission for SLE. In the current work, we defined sustained remission by achieving first remission in RA or SLE, then to maintain such status for at least 8 months or more as sustained remission during at least 2 rheumatology clinic follow-up visits. 


\section{Laboratory assessments}

All patients were followed in the rheumatology clinic every 3 months, with clinical and laboratory assessments during each visit to evaluate the disease activity and confirm remission status. In all patients, the erythrocyte sedimentation rate (ESR) by Westergren method and complete blood count $(\mathrm{CBC})$ was taken. For RA patients, anti-cyclic citrullinated peptide antibodies (anti-CCP Abs) and rheumatoid factor (RF) were assessed using the chemiluminescence microparticle immunoassay (CMIA), Abbott, USA. For SLE patients, anti-nuclear antibodies (ANA) were assessed by the indirect immuneflorescence using Kallestad kit, Aesku System, Germany; C3, C4, serum creatinine, and anti-double stranded DNA by the indirect immune-fluorescence technique. Urine analysis was done chemically and microscopically with protein creatinine ratio, urine casts.

\section{Health-related quality of life}

Information about HRQOL was obtained using the Medical Outcomes Study 36-Item Short-Form Health Survey (SF-36) [27], which is a widely used tool for assessing HRQOL in patients with various rheumatic conditions, including RA and SLE $[6,11]$. The SF-36 contains 8 multi-item scales that assess the domains of: physical functioning (PF, 10 items), social functioning (SF, two items), role limitations due to physical health problems (RP, four items), role limitations due to emotional problems (RE, three items), mental health $(\mathrm{MH}$, five items), vitality (VT, four items), bodily pain (BP, two items), and general health perceptions (GH, five items). Transformed subscale scores range from 0 to 100, with 0 being the worst and 100 the best possible score.

The physical and mental components of the eight scales can be combined into two scales, the Physical Component Summary (PCS) and Mental Component Summary (MCS). Each of them aggregates four health domains. The PCS aggregates the PF, RP, BP, and GH domains, and the MCS aggregates the VT, SF, RE, and $\mathrm{MH}$ domains [28]. The validated Arabic version of the SF-36 was used. This version proved to be reliable in a previous study [29]. The SF-36 was filled in at baseline with active disease and after sustained remission.

We chose to measure function with SF-36 as this was a validated outcome measure in both RA and SLE, while the Health Assessment Questionnaire (HAQ) was only validated in RA patients.

\section{Ethics}

The study was approved by the local ethical research committee at Al Hada Armed Forces Hospital, KSA (Registration number H-02-T-078), and performed according to the 1964 Helsinki Declaration. All patients had provided written informed consent.

\section{Statistical analysis}

Data was analyzed using SPSS software version 22. Descriptive statistics were calculated as the mean \pm

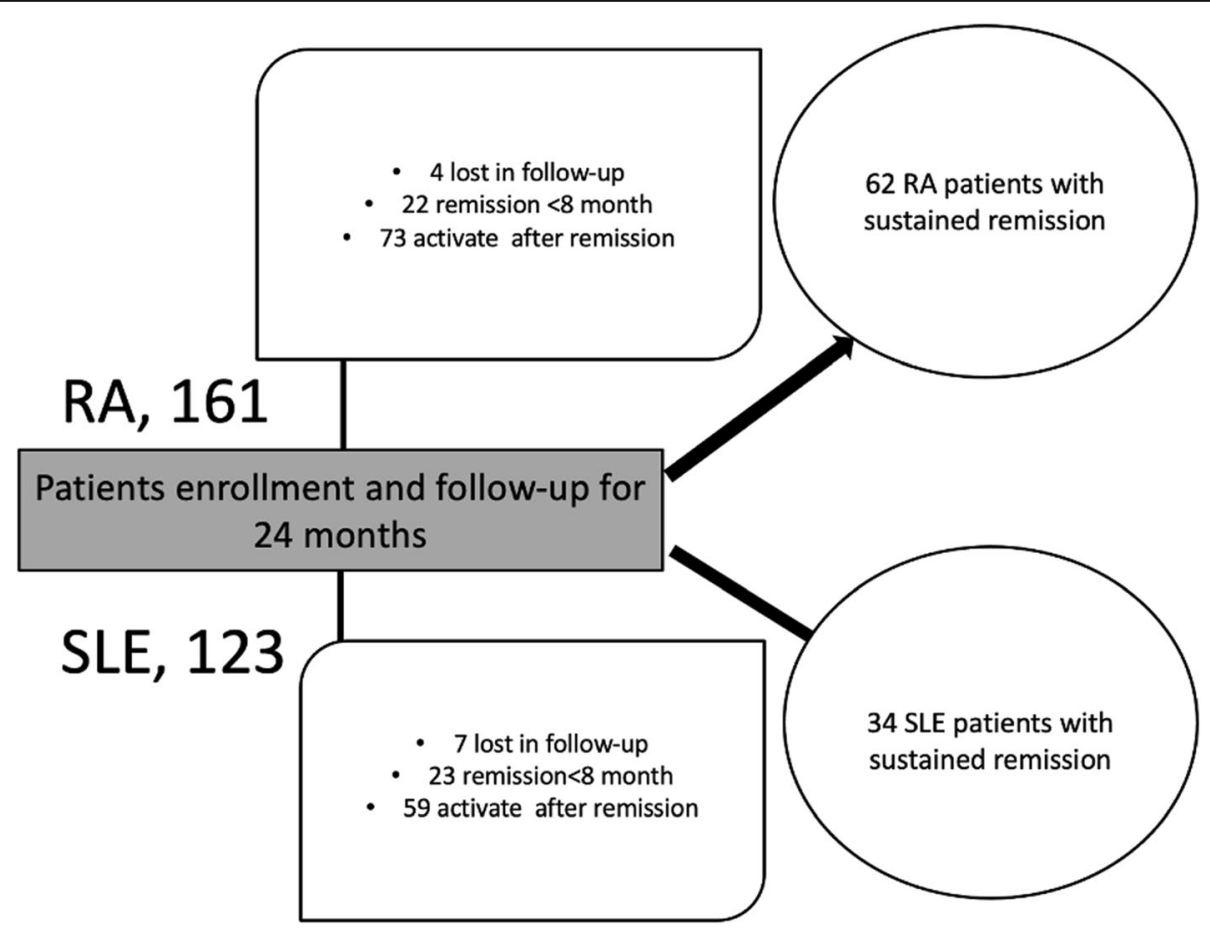

Fig. 1 Description of female RA and SLE cohorts 
Table 1 Clinical and demographic data of the studied groups

\begin{tabular}{|c|c|c|c|}
\hline & $\begin{array}{l}\text { RA }(N=62) \\
(\text { Mean } \pm \text { SD) }\end{array}$ & $\begin{array}{l}\text { SLE }(N=34) \\
(\text { Mean } \pm \text { SD) }\end{array}$ & $P$ value \\
\hline Age (years) & $35.9 \pm 6$ & $37.8 \pm 6$ & $p>0.05$ \\
\hline Disease duration (months) & $15.3 \pm 6$ & $17.1 \pm 6.8$ & $p>0.05$ \\
\hline ESR & $51.8 \pm 7.9$ & $29.3 \pm 15.3$ & $p<0.001$ \\
\hline Duration to induce remission (months) & $5.3 \pm 1.7$ & $7.1 \pm 2.3$ & $p<0.001$ \\
\hline DAS 28 & $5.3 \pm 1$ & - & \\
\hline SLEDAI & & $30.9 \pm 6.1$ & \\
\hline
\end{tabular}

standard deviation (SD) for numerical data and frequency and percentages for categorical data. Paired $t$ tests were applied to compare repeated measurements, and independent $t$ tests were used to compare scores between independent samples. Pearson correlations between disease activity and SF-36 scores were calculated. Correlations were interpreted as very low when $<0.30$, low when $0.30-0.50$, moderate when $0.50-0.70$, high when $0.70-0.90$, and very high when $>0.90$ [30]. Chisquared tests $\left(\chi^{2}\right)$ of independence were applied to compare categorical data. Significance level was set at $5 \%$ for all analyses.

\section{Results}

During the initial screening, 161 patients with active RA, and 123 patients with active SLE were included. Rheumatological medications used at baseline to induce remission were $92(57.2 \%)$ of the RA patients and 118 (94\%) of the SLE patients were on DMARDs either monotherapy or in combination. Of the RA patients, 69 (42.8\%) were treated with biologics (anti-TNF, Abatacept, Tocilizumab, Rituximab) either monotherapy or in combination with other DMARDs, and only 5 (4\%) of SLE patients were treated with biologics (one patient received Rituximab and 4 patients were on Belimumab).

\section{Patients achieving sustained remission}

Only patients in sustained remission were included in the current study. During follow-up, sustained remission was achieved by $62(38.5 \%)$ of the patients in the RA cohort and 34 (27.6\%) of the patients in the SLE cohort (Fig. 1).

The demographic characters of the RA and SLE patients were shown in Table 1. The average time needed to induce remission in RA was $5.3 \pm 1.7$ and $7.1 \pm 2.3$ months in RA and SLE patients, respectively, with statistically significantly longer duration to induce remission in SLE $(p=<0.001)$. No significant differences were found between RA and SLE patients with respect to their age and disease duration at inclusion in months. The RA patients had a significant higher ESR $(51.8 \pm 7.9$ vs 29.3 $\pm 15.3, p=<0.001$ ) than the SLE cases (Table 1).
At baseline, significant correlations were found between disease activity and PCS and MCS scores ( $p$ values $\leq 0.001)$ in both RA and SLE groups. This correlation was strong and negative with PCS and MCS ( $r$ 's 0.73 to -0.80 ) in both groups (Table 2).

SLE patients had significantly better scores on all SF36 subscales compared to RA patients during active disease. After achieving sustained remission status, the SF36 scores had improved in both cohorts, where RA patients now scored significantly better when compared to SLE groups for three subscales (GH, BP, PF) and for the total PCS score (Fig. 2). The mean values of PCS and MSC components scores of the SF-36 of the RA and SLE cohorts showed highly significant improvements after remission $(p \leq 0.001)$ (Table 3$)$.

\section{Discussion}

SLE and RA are both autoimmune disorders that have a significant effect on physical and mental health $[5,13]$. In active disease, the caregivers' psychological burden increases [31]. We aimed to assess the relation of disease activity with HRQOL, as well as the impact of sustained remission, which has hardly been studied in Arab patients.

The present prospective study revealed that $38.5 \%$ of the RA cohort could achieve sustained remission for 8 months or more, compared to $27.6 \%$ of the SLE cohort. Comparable figures were found by Pascual-Ramos et al. who found that $58 \%$ of RA patients achieved sustained remission compared to $30.6 \%$ of SLE patients [18]. This

Table 2 Correlation between disease activity in both female cohorts and physical and mental component summary scores of SF-36

\begin{tabular}{lll}
\hline $\begin{array}{l}\text { Groups } \\
\text { of } \\
\text { patients }\end{array}$ & DAS28 RA $(\boldsymbol{N}=\mathbf{6 2})$ & SLEDAI SLE $(\boldsymbol{N}=\mathbf{3 4})$ \\
\hline PCS & $-0.50(<0.001)$ & $\boldsymbol{r}(\boldsymbol{p})$ \\
MCS & $-0.46(<0.001)$ & $-0.64(<0.001)$ \\
\hline
\end{tabular}

Abbreviations: SF-36 Study 36-Item Short-Form Health Survey, DAS28 Disease activity score, RA Rheumatoid arthritis, SLEDAI Systemic Lupus Disease Activity Index, SLE Systemic lupus erythematosus, PCS Physical components summary of the SF-36, MCS Mental components summary of the SF-36, $\rho$ Spearman's rho 


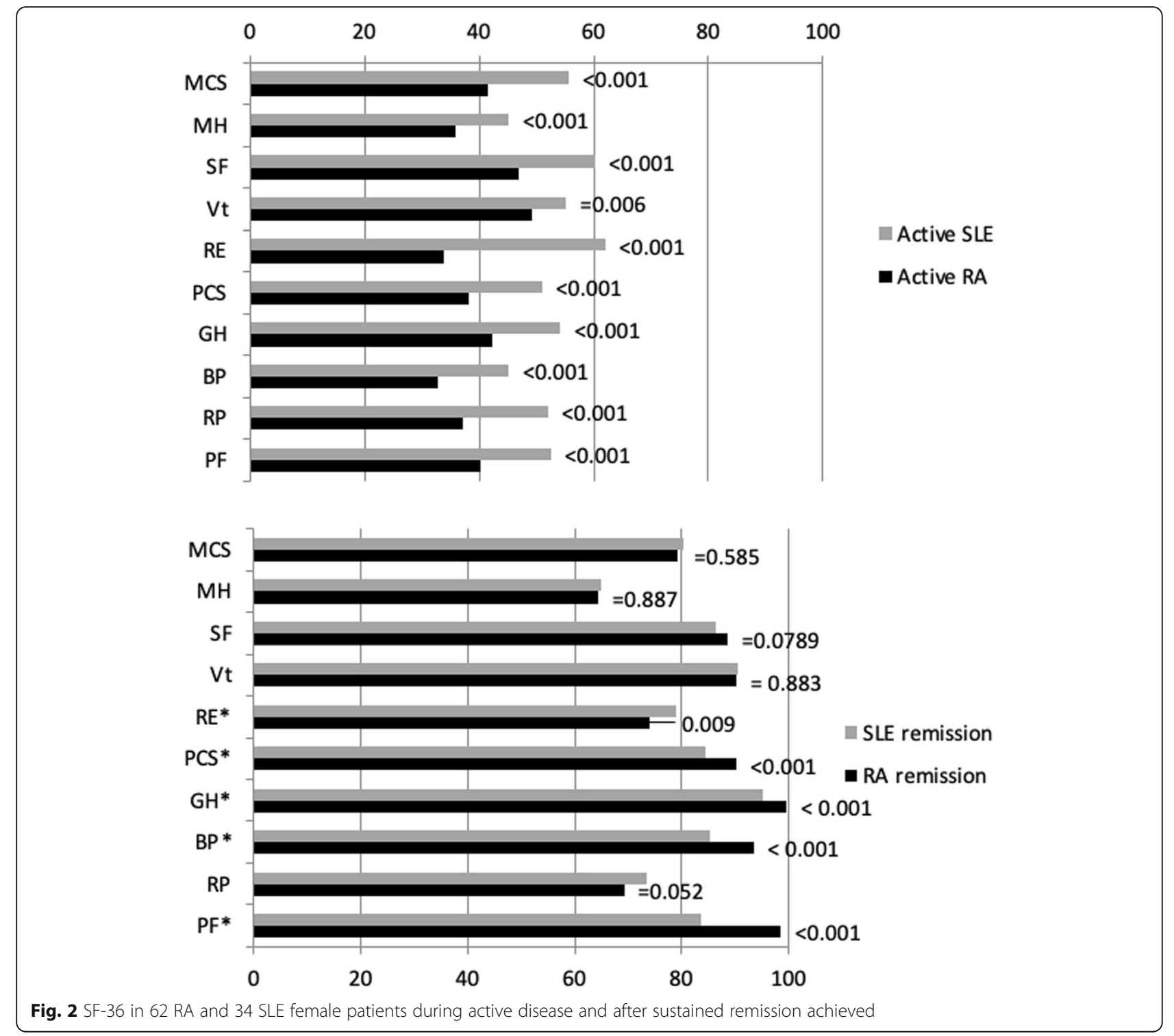

difference was explained by the effect of new RA medications and treatment strategies [32]. The PCS portion of the SF-36 has been linked to SLE disease activity and organ damage in previous SLE studies $[17,33]$. In the current research, SLE patients in sustained remission had a substantial increase in the MCS domain as compared to those with active disease. In comparison to this finding, Tsang-A-Sjoe et al. found that during the 2 years of the study, MCS scores did not vary between patients with active disease and those in remission in a longitudinal study of SLE patients [16]. A slightly higher percent of sustained remission among SLE patients was found in a recent retrospective study, where $42.2 \%$ of the 237 SLE patients achieved sustained remission [15].

HRQOL concerns the physical and functional health, and reflects a view of patients' social environment and

Table 3 Comparison between PCS and MSC components scores among female RA and SLE cohorts before and after remission

\begin{tabular}{|c|c|c|c|c|c|c|c|c|}
\hline \multirow[t]{2}{*}{ Parameter } & \multicolumn{4}{|l|}{$\mathrm{RA}(N=62)$} & \multicolumn{4}{|l|}{ SLE $(N=34)$} \\
\hline & Before & After & $t$ & $p$ value & Before & After & $t$ & $p$ value \\
\hline PCS & $38.10 \pm 5.66$ & $90.27 \pm 5.59$ & 59.1 & $<0.001$ & $51.01 \pm 10.9$ & $84.43 \pm 5.65$ & 14.6 & $<0.001$ \\
\hline MSC & $41.44 \pm 2.92$ & $79.33 \pm 9.24$ & 29.5 & $<0.001$ & $55.66 \pm 11$ & $80.23 \pm 6.75$ & 10.3 & $<0.001$ \\
\hline
\end{tabular}

Paired $t$ test

Abbreviations: SF-36 36-Item Short-Form Health Survey, DAS28 Disease activity score, RA Rheumatoid arthritis, SLEDAl Systemic Lupus Disease Activity Index, SLE Systemic lupus erythematosus, PCS Physical components summary of the SF-36, MCS Mental components summary of the SF-36 
psychological beliefs [34]. In the present study, a significant correlation was found between disease activity on one side, and physical and mental health scores on the other side, in both RA and SLE cohorts. This correlation was negative and strong with both the PCS and MCS components of HRQOL. This finding is consistent with those reported in other studies proving an effect of disease activity in RA and SLE patients on the HRQOL [4, $5,12,16,34,35]$. These studies concluded the negative impact of both diseases on the patients' physical, emotional, and social functioning, and higher HRQOL and functional capacity at lower disease activity levels.

In the present study, at baseline, the SLE cohort had significantly better SF-36 subscale scores compared to the RA cohort during active disease. The same observation of this baseline difference was present in only one prospective study in a Mexican population [18]. The worse SF-36 scores among RA patients at baseline could be ascribed to high disease activity and the higher pain experience [36]. When in remission, the SF-36 scores were strongly improved in both cohorts. RA patients in sustained remission have been found to have better HRQOL and function, and lower rates of radiological damage compared with patients with higher disease activity states. This is the basis of the "treat to target" (T2T) strategy [37, 38]. Recently, a T2T approach for SLE was also established using remission criteria in SLE (DORIS) [24].

In the present study, a highly significant improvement was found in both the mean values of PCS and MSC scores for RA and SLE cohorts after remission. Studies done in RA patients showed that the PCS scores of the SF-36 questionnaire among patients with low disease activity were significantly higher when compared to those with moderate and high disease activity scores. This finding is in accordance with a study in Egypt, where a close relationship was found between the disease activity score and the magnitude of joint inflammation and destruction in RA patients with the scores of the physical domains of HRQOL [5]. The improvement of the MCS scores among RA patients after remission was also observed by Pascual-Ramos et al. who found a significant improvements in the VT and SF domains of the MCS among RA patients after remission [18]. The same was reported by Dalves et al. who found a significant improvement of both ER and MH domains of the MCS after remission [13]. The improvements in the current study were very large in the RA sample, which may be explained by the fact that we only included RA patients with sustained remission and not those with low disease activity.

In previous SLE studies, the PCS component of the SF-36 was found to be strongly related with SLE disease activity and organ damage $[17,33]$. In the current study, there was also a significant improvement in the MCS domain in SLE patients with sustained remission in comparison to those with active disease. In contrast to this result, in a prospective study done by Tsang-A-Sjoe et al. in SLE patients, the MCS scores at baseline and at last visit did not differ in patients with active disease and those in remission during the 2 years of the study [16]. The difference with our study may be explained by the strict inclusion criteria applied in our study, excluding SLE patients with current active neuropsychiatric lupus. Furthermore, our cohort is considering a different ethnic group. A difference between ethnic groups was also observed by Tsang A Shoe et al. who found that the MCS domain was positively associated with Caucasian ethnicity and that disease activity could differ between different ethnic groups [16].

The present study showed that a significant improvement in the SF-36 scores was observed in RA patients compared to SLE patients after remission in four subscales: general health, bodily pain, and physical functioning, while the opposite was true for the role participation with emotional health problems. The PCS component of the SF-36 scale aggregates the PF, RP, BP, and GH domains, which means that most of the PCS domains of RA patients were improved with remission. In the same time, a non-significant difference was found between the patients in remission from the two cohorts regarding all the MCS components scores. These observed findings related to SF-36 MSC and PSC component scores between the RA and SLE cohorts were also observed in a study by Pascual-Ramos et al. [18] where no significant changes were reported for the MCS component between the two studied cohorts. At the same time, RA patients in that study also scored better than SLE patients on the physical health component summary.

The smaller improvement of SF-36 scores among the SLE cohort compared to the RA cohort in the present study could be explained by the extensive physical, psychological, and social challenges faced by SLE patients. In addition, in other studies, the musculoskeletal manifestation of SLE was found to worsen the eight HRQOL domains especially, pain, fatigue, and burden to others [11, 39]. Another explanation could be the known musculoskeletal and mucocutaneous manifestations of SLE, besides the systemic inflammation affecting internal organs as the lungs, and heart, kidney, heart, and the GIT and sometimes causing neuropsychiatric symptoms [10, 11].

In a study done on 69 SLE patients in China, patients who remitted for 5 years or more were found to have a significant lower prevalence of renal involvement, leucopenia, or thrombocytopenia; moreover, it was associated with significantly better total health-related scores of the 
Lupus Patient Reported Outcome [33]. An Italian study followed HRQOL in SLE patients who had been in remission. It was found that patients in prolonged remission for more than 5 years showed significantly better scores in the PF, RP, BP, GH, and SF components of the SF36 when compared with those in remission less than 5 years or unremitted [39].

The T2T strategy is a new treatment paradigm for RA and SLE patients that focuses on achieving remission or low disease activity score [40]. However, the effectiveness of the T2T approach in SLE patients has not yet been proven in a clinical trial, especially not for DORIS remission criteria [24]. Therefore, the study of patients in sustained remission (in accordance with valid T2T remission criteria) showing impact on outcomes as HRQOL, is essential to validate remission criteria.

A strength of our study is that we compared the correlation of disease activity with HRQOL in both RA and in SLE patients, which has hardly been done before in Saudi. A further strength of the current work is the assessment of impact not only of disease activity but also of the sustained remission criteria according to T2T approach in SLE and RA patients' mental and functional status. It is also a strength that it is the first or one of the first studies in a Saudi population.

A limitation of the present study could be the rather small sample size especially for the analyses of patients in remission. Not compared to control group. Also, the fact that only female patients were studied means that the results cannot be generalized to the total RA and SLE population; however, most of patients affected in both diseases are females. In addition, the study was conducted in only one center and in patients with Arab ethnicity and the study results may not be generalizable to different ethnicities.

\section{Conclusions}

Both SLE and RA patients in sustained remission strongly improved HRQOL domains. When in remission, RA patients had comparable or better HRQOL than SLE patients. Thus, it may be expected that early disease control and remission will be associated with better HRQOL outcome. Future prospective studies with a longer follow-up period are needed.

\footnotetext{
Abbreviations

SF-36: 36-Item Short-Form Health Survey; RA: Rheumatoid Arthritis, SLE Systemic Lupus Erythematosus; PF: Physical functioning; RP: Role physical; BP: Bodily pain; GH: General health; PCS: Physical component summary; RE: Role emotional; VT: Vitality; SF: Social functioning; MH: Mental health; MCS: Mental component summary; HRQOL: Health-related quality of life; ACR: American College of Rheumatology; SLEDAl: Systemic Lupus Disease Activity Index scores; ESR: Erythrocyte sedimentation rate; CBC: Complete blood count; Anti-CCP Abs: Anti-cyclic citrullinated peptide antibodies; RF: Rheumatoid factor; CMIA: Chemiluminescence microparticle immunoassay; ANA: Anti-nuclear antibodies; T2T: Treat to target
}

\section{Acknowledgements}

We thank the participating patients for their cooperation.

\section{Authors' contributions}

BE collected the clinical data and contributed in writing the manuscript. AT analyzed and interpreted the patient data. DD gave the main idea, contributed in writing the manuscript, and interpreted the patient data. SA collected the data. ER collected and interpreted the clinical data. AA collected the data. MA contributed to the reference collection. PT contributed to collecting references and contributed in writing the manuscript. JR supervised and gave final approval. All authors read and approved the final manuscript.

\section{Funding}

No funding was received from any source.

\section{Availability of data and materials}

The data is available upon request.

\section{Declarations}

\section{Ethics approval and consent to participate}

The study was approved by the local ethical research committee at Al Hada Armed Forces Hospital, KSA (Registration number H-02-T-078), and performed according to the 1964 Helsinki Declaration. All patients had provided written informed consent.

\section{Consent for publication}

Not applicable.

\section{Competing interests}

The authors have no financial or personal relationships or interests regarding this study.

\section{Author details}

${ }^{1}$ Department of Rheumatology, Rehabilitation and Physical Medicine, Benha University, Banha, Egypt. ${ }^{2}$ Rheumatology Department, Al-Hada Armed Forces Hospital, Taif, Saudi Arabia. ${ }^{3}$ Department of Public Health and Community Medicine, Faculty of Medicine, Menoufia University, Shibin El Kom, Egypt. ${ }^{4}$ Department of Family and Community Medicine, College of Medicine, Taif University, Taif, Saudi Arabia. ${ }^{5}$ Neuropsychiatry Department, Benha University, Banha, Egypt. ${ }^{6}$ Department of Rheumatology, Rehabilitation and Physical Medicine, Tanta University, Tanta, Egypt. 'Internal Medicine Department, Taif University, Taif, Saudi Arabia. ${ }^{8}$ Internal Medicine Department, Al-Hada Armed Forces Hospital, Taif, Saudi Arabia. ${ }^{9}$ Faculty of Behavioral, Management and Social sciences, Department Psychology, Health and Technology, University of Twente, Enschede, The Netherlands.

Received: 25 March 2021 Accepted: 19 April 2021

Published online: 01 June 2021

References

1. Minaur NJ, Jacoby RK, Cosh JA, Taylor G, Rasker JJ (2004) Outcome after 40 years with rheumatoid arthritis: a prospective study of function, disease activity, and mortality. J Rheumatol 69:3-8

2. Marrie RA, Hitchon CA, Walld R, Patten SB, Bolton JM, Sareen J, Walker JR, Singer A, Lix LM, el-Gabalawy R, Katz A, Fisk JD, Bernstein CN, for the Canadian Institutes of Health Research Team in Defining the Burden and Managing the Effects of Psychiatric Comorbidity in Chronic Immunoinflammatory Disease (2018) Increased burden of psychiatric disorders in rheumatoid arthritis. Arthritis Care Res 70(7):970-978. https:// doi.org/10.1002/acr.23539

3. Matcham F, Rayner L, Steer S, Hotopf M (2013) The prevalence of depression in rheumatoid arthritis: a systematic review and meta-analysis. Rheumatol (United Kingdom) 52(12):2136-2148

4. Rathbun AM, Harrold LR, Reed GW (2015) Temporal associations between the different domains of rheumatoid arthritis disease activity and the onset of patient-reported depressive symptoms. Clin Rheumatol 34(4):653-663. https://doi.org/10.1007/s10067-014-2759-z

5. Gamal RM, Mahran SA, Abo El Fetoh N, Janbi F (2016) Quality of life assessment in Egyptian rheumatoid arthritis patients: relation to clinical 
features and disease activity. Egypt Rheumatol 38(2):65-70. https://doi.org/1 0.1016/j.ejr.2015.04.002

6. Katchamart W, Narongroeknawin P, Chanapai W, Thaweeratthakul P (2019) Health-related quality of life in patients with rheumatoid arthritis. BMC Rheumatol 3(1):34. https://doi.org/10.1186/s41927-019-0080-9

7. Ghodke-Puranik Y, Niewold TB (2015) Immunogenetics of systemic lupus erythematosus: a comprehensive review. J Autoimmun 64:125-136. https:// doi.org/10.1016/j.jaut.2015.08.004

8. Palagini L, Mosca M, Tani C, Gemignani A, Mauri M, Bombardieri S (2013) Depression and systemic lupus erythematosus: a systematic review. Lupus 22(5):409-416. https://doi.org/10.1177/0961203313477227

9. Zhang L, Fu T, Yin R, Zhang Q, Shen B (2017) Prevalence of depression and anxiety in systemic lupus erythematosus: a systematic review and metaanalysis. BMC Psychiatry 17(1):1-14

10. Barraclough M, McKie S, Parker B, Jackson A, Pemberton P, Elliott R, Bruce IN (2019) Altered cognitive function in systemic lupus erythematosus and associations with inflammation and functional and structural brain changes. Ann Rheum Dis 78(7):934-940. https://doi.org/10.1136/annrheumdis-201 8-214677

11. Piga M, Congia M, Gabba A, Figus F, Floris A, Mathieu A, Cauli A (2018) Musculoskeletal manifestations as determinants of quality of life impairment in patients with systemic lupus erythematosus. Lupus 27(2):190-198. https:// doi.org/10.1177/0961203317716319

12. Alsowaida N, Alrasheed M, Mayet A, Alsuwaida A, Omair MA (2018) Medication adherence, depression and disease activity among patients with systemic lupus erythematosus. Lupus 27(2):327-332. https://doi.org/10.1177/ 0961203317725585

13. Rosa-Gonçalves D, Bernardes $M$, Costa L (2018) Quality of life and functional capacity in patients with rheumatoid arthritis - cross-sectional study. Reumatol Clin 14(6):360-366. https://doi.org/10.1016/j.reuma.2017.03.002

14. Zhang $L$, Cai $P$, Zhu W (2020) Depression has an impact on disease activity and health-related quality of life in rheumatoid arthritis: a systematic review and meta-analysis. Int J Rheum Dis 23(3):285-293. https://doi.org/10.1111/1 756-185X.13774

15. Poomsalood N, Narongroeknawin P, Chaiamnuay S, Asavatanabodee P, Pakchotanon R (2019) Prolonged clinical remission and low disease activity statuses are associated with better quality of life in systemic lupus erythematosus. Lupus 28(10):1189-1196. https://doi.org/10.1177/096120331 9862614

16. Tsang-A-Sjoe MWP, Bultink IEM, Heslinga M, Van Tuyl LH, Van Vollenhoven RF, Voskuyl AE (2019) The relationship between remission and healthrelated quality of life in a cohort of SLE patients. Rheumatol (United Kingdom) 58(4):628-635

17. Mok CC, Ho LY, Tse SM, Chan KL (2017) Prevalence of remission and its effect on damage and quality of life in Chinese patients with systemic lupus erythematosus. Ann Rheum Dis 76(8):1420-1425. https://doi.org/10.1136/a nnrheumdis-2016-210382

18. Pascual-Ramos V, Contreras-Yáñez I, Valencia-Quiñones KR, Romero-Díaz J (2018) Rheumatoid arthritis patients achieved better quality of life than systemic lupus erythematosus patients at sustained remission. Clin Exp Rheumatol 36(4):619-626

19. Aletaha D, Neogi T, Silman AJ, Funovits J, Felson DT, Bingham CO et al (2010) 2010 Rheumatoid arthritis classification criteria: an American College of Rheumatology/European League Against Rheumatism collaborative initiative. Arthritis Rheum 62(9):2569-2581. https://doi.org/10.1002/art.27584

20. van Riel PLCM, Renskers L (2016) The Disease Activity Score (DAS) and the Disease Activity Score using 28 joint counts (DAS28) in the management of rheumatoid arthritis. Clin Exp Rheumatol 34(5 Suppl 101):S40-S44

21. Inês L, Silva C, Galindo M, Lõpez-Longo FJ, Terroso G, Romão VC et al (2015) Classification of systemic lupus erythematosus: Systemic Lupus Intemational Collaborating Clinics versus American College of Rheumatology criteria. A comparative study of 2,055 patients from a real-life, international systemic lupus erythematosus cohort. Arthritis Care Res 67(8):1180-1185. https:/doi.org/10.1002/acr.22539

22. Bombardier C, Gladman DD, Urowitz MB, Caron D, Chang CH, Austin A, Bell A, Bloch DA, Corey PN, Decker JL, Esdaile J, Fries JF, Ginzler EM, Goldsmith $\mathrm{CH}$, Hochberg MC, Jones JV, Riche NGHL, Liang MH, Lockshin MD, Muenz LR, Sackett DL, Schur PH (1992) Derivation of the SLEDAI. A disease activity index for lupus patients. Arthritis Rheum 35(6):630-640. https://doi.org/10.1 002/art.1780350606

23. Gladman DD, Ibañez D, Urowitz MB (2002) Systemic lupus erythematosus disease activity index 2000. J Rheumatol 29(2):288-291
24. Van Vollenhoven R, Voskuyl A, Bertsias G, Aranow C, Aringer M, Arnaud $L$ et al (2017) A framework for remission in SLE: Consensus findings from a large international task force on definitions of remission in SLE (DORIS). Ann Rheum Dis 76(3):554-561. https://doi. org/10.1136/annrheumdis-2016-209519

25. Smolen JS, Landewé R, Bijlsma J, Burmester G, Chatzidionysiou K, Dougados M, Nam J, Ramiro S, Voshaar M, van Vollenhoven R, Aletaha $D$, Aringer $M$, Boers $M$, Buckley $C D$, Buttgereit $F$, Bykerk $V$, Cardiel M, Combe B, Cutolo M, van Eijk-Hustings Y, Emery P, Finckh A, Gabay C, Gomez-Reino J, Gossec L, Gottenberg JE, Hazes JMW, Huizinga T, Jani M, Karateev D, Kouloumas M, Kvien T, Li Z, Mariette X, Mclnnes I, Mysler E, Nash P, Pavelka K, Poór G, Richez C, van Riel P, Rubbert-Roth A, Saag K, da Silva J, Stamm T, Takeuchi T, Westhovens R, de Wit M, van der Heijde D (2017) EULAR recommendations for the management of rheumatoid arthritis with synthetic and biological disease-modifying antirheumatic drugs: 2016 update. Ann Rheum Dis 76(6):960-977. https://doi.org/10.1136/a nnrheumdis-2016-210715

26. Ruiz-Irastorza G, Khamashta MA (2011) Lupus and pregnancy: integrating clues from the bench and bedside. Eur J Clin Invest 41(6):672-678. https:// doi.org/10.1111/.1.1365-2362.2010.02443.x

27. Ware JE Jr, Sherbourne CD (1992) The MOS 36-item short-form health survey (SF-36). I. Conceptual framework and item selection. Med Care 30(6): 473-483. https://doi.org/10.1097/00005650-199206000-00002

28. Ware JE Jr (2000) SF-36 health survey update. Spine (Phila Pa 1976) 25(24): 3130-3139. https://doi.org/10.1097/00007632-200012150-00008

29. El-Kalla RA, Abd MM, Khalaf E-K, Mammdooh, Saad AA, Othman EM (2016) Reliability of the Arabic Egyptian version of short form 36 health survey questionnaire to measure quality of life in burned patient. Med J Cairo Univ 8(2):311-316

30. Hinkle DE, Wiersma W, Jurs SG (2003) Applied statistics for the behavioral sciences. 5th ed. Houghton Mifflin Co, Boston

31. Coskun Benlidayi I, Gokcen N, Sariyildiz A, Sarpel T (2019) They have got the blues: patient's mood-and disease activity-related psychological burden of rheumatoid arthritis on caregivers. Int J Psychiatry Clin Pract 23(2):84-89. https://doi.org/10.1080/13651501.2018.1492728

32. Nagy G, van Vollenhoven RF (2015) Sustained biologic-free and drug-free remission in rheumatoid arthritis, where are we now? Arthritis Res Ther 17(1):181. https://doi.org/10.1186/s13075-015-0707-1

33. Bruce IN, O'Keeffe AG, Farewell V, Hanly JG, Manzi S, Su L et al (2015) Factors associated with damage accrual in patients with systemic lupus erythematosus: results from the Systemic Lupus International Collaborating Clinics (SLICC) Inception Cohort. Ann Rheum Dis 74(9):1706-1713. https:// doi.org/10.1136/annrheumdis-2013-205171

34. Dua AB, Touma Z, Toloza S, Jolly M (2013) Top 10 recent developments in health-related quality of life in patients with systemic lupus erythematosus topical collection on systemic lupus erythematosus. Curr Rheumatol Rep 15(12):380. https://doi.org/10.1007/s11926-013-0380-9

35. Drenkard C, Villa AR, García-Padilla C, Pérez-Vázquez ME, AlarcónSegovia D (1996) Remission of systemic lupus erythematosus. Medicine (Baltimore) 75(2):88-98. https://doi.org/10.1097/00005792-1 99603000-00005

36. Matcham F, Scott IC, Rayner L, Hotopf M, Kingsley GH, Norton S et al (2014) The impact of rheumatoid arthritis on quality-of-life assessed using the SF36: a systematic review and meta-analysis. Semin Arthritis Rheum 44:123130

37. Radner H, Smolen JS, Aletaha D (2014) Remission in rheumatoid arthritis: benefit over low disease activity in patient-reported outcomes and costs. Arthritis Res Ther 16(1):R56. https://doi.org/10.11 86/ar4491

38. Versteeg GA, Steunebrink LMM, Vonkeman HE, ten Klooster PM, van der Bijl AE, van de Laar MAFJ (2018) Long-term disease and patient-reported outcomes of a continuous treat-to-target approach in patients with early rheumatoid arthritis in daily clinical practice. Clin Rheumatol 37(5):11891197. https://doi.org/10.1007/s10067-017-3962-5

39. Chaigne B, Chizzolini C, Perneger T, Trendelenburg M, Huynh-Do U, Dayer E et al (2017) Impact of disease activity on health-related quality of life in systemic lupus erythematosus - a cross-sectional analysis of the Swiss Systemic Lupus Erythematosus Cohort Study (SSCS). BMC Immunol 18(1):17

40. Smolen JS, Breedveld FC, Burmester GR, Bykerk V, Dougados M, Emery P, Kvien TK, Navarro-Compán MV, Oliver S, Schoels M, Scholte-Voshaar M, 
Stamm T, Stoffer M, Takeuchi T, Aletaha D, Andreu JL, Aringer M, Bergman M, Betteridge N, Bijlsma H, Burkhardt H, Cardiel M, Combe B, Durez P,

Fonseca JE, Gibofsky A, Gomez-Reino JJ, Graninger W, Hannonen P, Haraoui B, Kouloumas M, Landewe R, Martin-Mola E, Nash P, Ostergaard M, Östör A, Richards P, Sokka-Isler T, Thorne C, Tzioufas AG, van Vollenhoven R, de Wit M, van der Heijde D (2016) Treating rheumatoid arthritis to target: 2014 update of the recommendations of an international task force. Ann Rheum Dis 75(1):3-15. https://doi.org/10.1136/annrheumdis-2015-207524

\section{Publisher's Note}

Springer Nature remains neutral with regard to jurisdictional claims in published maps and institutional affiliations.

\section{Submit your manuscript to a SpringerOpen ${ }^{\circ}$ journal and benefit from:}

- Convenient online submission

- Rigorous peer review

- Open access: articles freely available online

- High visibility within the field

- Retaining the copyright to your article

Submit your next manuscript at $\boldsymbol{\nabla}$ springeropen.com 